\title{
RELAC̣ÕES DO BRASIL COM ÁFRICA DO SUL E ANGOLA: ESFORÇOS PARA A MANUTENÇÃO DA SEGURANÇA NO ATLÂNTICO SUL
}

\author{
Luiz Rogério Franco Goldoni ${ }^{1}$ \\ Sandro de Nazareth Ciribelli
}

\section{Introdução}

O presente trabalho investiga as relações do Brasil com África do Sul e Angola, nos campos da política, economia e defesa, no período compreendido entre 2003 a 20I4. Mais especificamente são averiguadas as cooperações estabelecidas no âmbito da Defesa e seus efeitos para a manutenção da segurança no Atlântico Sul. Em relação aos procedimentos metodológicos, optou-se pela pesquisa bibliográfica e documental, do tipo qualitativa, já que se almejou identificar, descrever e interpretar os aspectos analisados em relação ao referido estudo.

O mar sempre esteve relacionado com o progresso do Brasil. Foi a via do descobrimento, da colonização, das invasões estrangeiras, da consolidação da independência e do comércio exterior (Guerra 20II). Mesmo com os avanços tecnológicos e o surgimento de sociedades pós-industriais, aquele ambiente físico continua como elemento significativo para a compreensão da política e das relações internacionais (Dougherty e Pfaltzgraff 2003). Nesse contexto, a relevância do ambiente marítimo reside, dentre outros aspectos,

\footnotetext{
I Doutor em Ciência Política pela Universidade Federal Fluminense. Professor do Programa de Pós-Graduação em Ciências Militares (PPGCM) do Instituto Meira Mattos da Escola de Comando e Estado-Maior do Exército (ECEME).E-mail: luizrfgoldoni@gmail.com

2 Pós-Graduado em Ciências Militares pela Escola de Aperfeiçoamento de Oficiais. Atualmente é aluno do Curso de Altos Estudos Militares da Escola de Comando e Estado-Maior do Exército, realizando especialização latu sensu em Ciências Militares, pelo Instituto Meira Mattos de Estudos Políticos e Estratégicos. E-mail: ac.ciribelli@gmail.com
} 
no fato de cobrir cerca de $70 \%$ da superfície terrestre e, principalmente, por representar fonte de riquezas e vias de comunicação que unem os diversos continentes (Silva 20I4, I99).

O Atlântico Sul é uma via de transporte e comunicação fundamental para o Brasil, e constitui um espaço de elevada importância para a defesa e a segurança dos países por ele banhados. Sua importância estratégica é respaldada por suas riquezas naturais, ${ }^{3}$ seus alcances e dimensões, além do fato de servir como rota comercial por onde circula em torno de $90 \%$ do comércio exterior brasileiro (Neves 2013).

Mais recentemente, questões de segurança e assuntos relacionados à defesa vêm obtendo valor no pensamento estratégico brasileiro. Notadamente, a importância crescente dada aos recursos marítimos como objeto de defesa nacional transparece nos principais documentos da defesa brasileira contemporânea, como a Política Nacional de Defesa (PND), a Estratégia Nacional de Defesa (END) e o Livro Branco de Defesa Nacional (LBDN). ${ }^{4}$ Os documentos apresentam o oceano Atlântico como vital para o País e estabelecem os passos para assegurar a soberania brasileira sobre o seu espaço marítimo. ${ }^{5}$

Dentre os principais objetivos da nova estratégia voltada para o cenário externo definidos na PND e na $\mathrm{END}^{6}{ }^{6}$ o governo brasileiro propõe uma nova política externa capaz de integrar plenamente suas ações diplomáticas com suas políticas de defesa e desenvolvimento econômico e, ao mesmo tem-

3 Ressalta-se que mais de $90 \%$ do petróleo produzido no Brasil vem de plataformas offshore (Abdenur e Souza Neto 20I4a).

4 A PND e a END foram criadas em 2008, sendo atualizadas no ano de 2012 , ano de publicação do LBDN.

5 Segundo a PND, o Brasil visualiza um entorno estratégico que extrapola a região sul-americana e inclui o Atlântico Sul e os países lindeiros da África, assim como a Antártica. De acordo com a END, o Brasil precisa manter a capacidade focada de projeção de poder e criar condições para controlar, no grau necessário à defesa e dentro dos limites do direito internacional, as áreas marítimas e águas interiores de importância político-estratégica, econômica e militar, e também as suas linhas de comunicação marítimas.

6 Dentre os objetivos estratégicos definidos na END para a Marinha Brasileira, destacam-se "a prontidão para responder a qualquer ameaça, por Estado ou por forças não convencionais ou criminosas, às vias marítimas de comércio, e a capacidade de participar de operações internacionais de paz, fora do território e das águas jurisdicionais brasileiras, sob a égide das Nações Unidas ou de organismos multilaterais da região" (Brasil 20I2b, ıо). Cabe ressaltar que parte importante da END é o Programa de Desenvolvimento de Submarinos (PROSUB), em conjunto com a França, que visa construir em solo nacional quatro submarinos convencionais e um de propulsão nuclear. Ao concluir o Programa, o país terá um importante ganho estratégico para a defesa da costa brasileira, pois além de aumentar sua projeção de poder, proporcionará à Marinha melhores condições de realizar o controle das áreas marítimas (Gonçalves e Corbellini 20I4). 
po, propõe um conceito novo na história brasileira: o entorno estratégico7. A respeito das relações do Brasil com países no seu entorno estratégico, Abdenur e Souza Neto (20I4a, 5) argumentam que:

Nos últimos anos, o governo brasileiro tem intensificado os seus esforços de cooperação - inclusive em defesa - com os países no perímetro do Atlântico Sul. Destacando a sua condição de país sul-atlântico, o Brasil busca uma aproximação com Estados da costa ocidental da África, não apenas com parceiros históricos, tais como Angola, Nigéria e África do Sul. Frente a um cenário em que o Atlântico Sul assume nova importância geopolítica, tanto para os atores da região quanto para os de fora, o Brasil utiliza a cooperação para promover a construção de uma identidade regional que começa a alterar as relações de poder nesse espaço.

O governo brasileiro intensifica seus esforços de cooperação com países no perímetro do Atlântico Sul, dentre eles Angola e África do Sul. A diplomacia brasileira tem demonstrado que a cooperação com países africanos em desenvolvimento pode trazer retornos positivos para o Brasil, principalmente em assuntos que envolvam o seu entorno estratégico voltado para a África. Abdenur e Souza Neto (20I4b, 232) assinalam que:

O governo brasileiro vem se esforçando não apenas para ampliar seus laços e parcerias de forma concreta, mas também de forma a fortalecer a construção de uma identidade comum com os países da costa ocidental da África [...] Tais esforços bi e multilaterais ocorrem paralelamente aos esforços de modernização do poder militar brasileiro - um programa respaldado, na sua dimensão marítima, pelo argumento de que é necessário proteger os recursos naturais - atuais e potenciais - no Atlântico Sul.

As recentes descobertas de petróleo no Brasil, bem como o incremento da produção na costa africana, têm contribuído para o crescimento da importância do Atlântico Sul no cenário externo. Para o Brasil, esse Oceano representa um elemento fundamental na sua defesa, além de servir como via de projeção marítima internacional, implicando em assuntos de segurança que envolvem o País (Nasser e Moraes 20I4, I4).

Num cenário em que o Atlântico Sul assume nova importância geopolítica, a cooperação entre Brasil, África do Sul e Angola contribui para maior aproximação política e possibilita o desenvolvimento eco-

7 Entorno estratégico compreende as regiões aonde o Brasil quer irradiar sua influência e liderança diplomática, econômica e militar. De acordo com o LBDN, essas regiões seriam a América do Sul, os países lindeiros da África, a Antártida e a Bacia do Atlântico Sul. 
nômico, além de fortalecer a discussão de assuntos na área de defesa considerados relevantes aos países envolvidos. Por certo, o Atlântico Sul tornou-se fator ainda mais relevante nas relações entre os Estados supracitados (Penha 20II).

\section{Projeção de poder brasileiro no Atlântico Sul}

O Atlântico Sul, além de rota de passagem e importante espaço geoeconômico, é, também, polo de desenvolvimento. Tal fato pode resultar num ambiente de competição intensa pelo controle de sua diversidade de recursos, inclusive por outras potências tradicionais ou emergentes (Pereira e Barbosa 20I2, 6I). Devido à importância daquele espaço - e também como forma de pleitear maiores recursos para sua defesa - o Almirante Roberto de Guimarães Carvalho criou, em 2004, o termo "Amazônia Azul".

De acordo com Wiesebron (2013), a área da Amazônia Azul abrange a Zona Econômica Exclusiva (ZEE) de 200 milhas náuticas, com uma superfície de $3.539 .919 \mathrm{~km}^{2}$, enquanto a Plataforma Continental (PC), até 350 milhas náuticas, corresponde a $960 \mathrm{mil} \mathrm{km}^{2}$ Somando-se ambas são obtidos aproximadamente 4,5 milhões de $\mathrm{km}^{2}$, equivalente a mais de $50 \%$ da extensão territorial brasileira (Brasil 20I2b e Brasil 20I3). Em 2004, o governo brasileiro apresentou uma proposta para o reconhecimento da PC na Comissão de Limites da Plataforma Continental (CLPC) da Organização das Nações Unidas (ONU) (Wiesebron 2013, IO9).

Da perspectiva de uma estratégia nacional, essa passagem da projeção continental para a marítima foi o resultado de um processo oriundo da política externa do país, que, nas últimas décadas, perseguiu a todo custo objetivos que visaram assegurar direitos e interesses no espaço marítimo do entorno regional estratégico, isto é, o Atlântico Sul (Costa 20I2).

A conquista pela extensão da PC envolveu movimentos decisivos em duas frentes principais. No plano externo, houve necessidade de intensas negociações diplomáticas perante a ONU. No cenário interno, essa iniciativa envolveu o Programa de Avaliação do Potencial Sustentável dos Recursos Vivos da Zona Econômica Exclusiva Brasileira (REVIZEE) e o Plano de Levantamento da Plataforma Continental Brasileira (LEPLAC), ambos liderados pela Marinha, apoiados diretamente pela Petrobras e com a participação de outras instituições nacionais (Costa 20I2, 5).

Essa integração - agregando as ações desenvolvidas pelo Itamaraty, pela Marinha do Brasil e demais instituições de pesquisas — foi responsável por gerar resultados significativos que permitiram ao país consolidar seus 
direitos e o consequente domínio legal em uma significativa faixa marítima no Atlântico Sul.

Como forma de legitimar suas reivindicações e também de projetar poder de forma "colaborativa", o Brasil tem auxiliado países da CPLP ${ }^{8}$ nos levantamentos de suas plataformas continentais e na preparação de propostas junto à Convenção das Nações Unidas sobre Direito do Mar. Conforme Abdenur e Souza Neto (20I4a, I5):

A maioria dos membros da CPLP está localizada na região do Atlântico Sul ou próximo dele. Em março de 2oıo, a organização lançou o projeto de um atlas dos oceanos da CPLP, e circularam propostas de cooperação entre os países-membros para extensão de suas plataformas continentais, com assistência brasileira, seguindo o modelo do Plano de Levantamento da Plataforma Continental Brasileira. Novas áreas de cooperação incluem programas de pesquisa referentes aos fundos marinhos, tais como o Programa de Prospecção e Exploração de Recursos Minerais da Área Internacional do Atlântico Sul e Equatorial (PROAREA) [...]. Finalmente, há iniciativas para a identificação de áreas estratégicas de interesse comum no âmbito de segurança e vigilância marítima.

Dessa forma, o Brasil dissemina sua abordagem no Atlântico Sul, usando a cooperação em defesa como meio de enfatizar preocupações em comum (Menezes 20I5).

Além dos esforços diplomáticos empreendidos, bem como o incremento de iniciativas visando fomentar o desenvolvimento econômico, o Brasil também investiu em programas de cooperação em defesa, como forma de ampliar as relações entre alguns países do Atlântico Sul. Embora o esforço principal da cooperação Sul-Sul brasileira fosse enfatizar os laços históricos e culturais com a África Lusófona, no que diz respeito à área de defesa, os acordos e iniciativas alcançaram um universo bem mais amplo, estabelecendo inclusive uma intenção de desenvolver cada vez mais a cooperação naval com diversos países africanos (Visentini 20II).

Outro importante fator que contribuiu para a aproximação do Brasil com países africanos foi a criação da Zona de Paz e Cooperação do Atlântico

8 A Comunidade dos Países de Língua Portuguesa (CPLP) foi criada em Lisboa, em julho de I996, com a finalidade de reunir os sete países lusófonos então existentes (...) em torno de três objetivos gerais, definidos nos Estatutos da Comunidade: a concertação político-diplomática entre seus membros; a cooperação econômica, social, cultural, jurídica e técnico-científica; e a promoção e difusão da Língua Portuguesa. Após sua independência, em 20 de maio de 2002 , o Timor Leste passou a ser o oitavo Estado-membro da Comunidade (Saraiva 20I5). 
Sul (ZOPACAS)9. Trata-se de uma aliança baseada na Cooperação Sul-Sul, com a missão de promover a cooperação regional e a manutenção da paz e segurança no Atlântico Sul. A Zona tem se configurado como um meio de integração regional, que objetiva também assegurar a defesa e a segurança dos interesses dos países membros na região, fomentando o desenvolvimento dos poderes navais, delimitando responsabilidades e buscando evitar interferências externas (Aguilar 2013).

O discurso brasileiro na ZOPACAS ressalta não apenas os interesses em comum entre os países atlânticos da América do Sul e da África, mas também a necessidade de minimizar a presença de atores externos. Como já observado por Miyamoto (1987), mesmo na sua versão original, o discurso oficial da ZOPACAS ressaltava a paz e a cooperação sem abrir mão da possibilidade de ampliação do poder naval dos países-membros.

Com o desenvolvimento da cooperação entre o Brasil e os países africanos, houve uma forte expansão dos atrativos empresariais para esse continente, seja a partir de investimento direto, financiamentos ou doações. No âmbito de defesa, a situação não foi diferente, e notou-se um aumento relativo da presença de empresas brasileiras de equipamentos militares na África, muitas em parceria com o governo.

A base de dados da Agência Brasileira de Cooperação (ABC) - que é um departamento do Ministério das Relações Exteriores - indica que o governo brasileiro tem atuado junto às Forças Armadas para a capacitação de militares em vários países africanos, entre eles Angola e África do Sul. O resumo de projetos indica que a cooperação Sul-Sul em defesa é bastante diversificada, acionando diferentes setores das Forças Armadas no desenho e na implementação de programas de treinamento, fornecimento de armas e equipamentos, colaboração em pesquisa - sobretudo levantamentos da plataforma continental, projetos de ciência e tecnologia e exercícios bilaterais ou multilaterais (Pereira e Barbosa 20I2).

A cooperação com a África também visa consolidar o apoio ao papel do Brasil na reforma da governança global, inclusive ao seu pleito a um assento permanente no Conselho de Segurança das Nações Unidas. Em 2003, no início do governo Lula, autoridades angolanas haviam manifestado apoio à reivindicação brasileira (Heleno e Martins 20I4). Ao longo dos anos seguintes, outros países da costa atlântica africana também expressaram seu apoio, dentre eles a África do Sul e alguns membros da CPLP.

Do lado africano, o interesse em cooperar com o Brasil - dentro e fora do âmbito militar — vem aumentando. E, à medida que o apoio africano

9 É formada por Brasil, Argentina e Uruguai e 2i países da costa oeste da África (Aguilar 20I3). 
ao pleito brasileiro por um assento permanente no Conselho de Segurança da ONU constitui um elemento estratégico para a diplomacia brasileira, o Brasil vem buscando intensificar suas negociações e ampliar sua base de apoio por meio das relações bilaterais com esses países emergentes.

\section{Relações Brasil - África do Sul}

A África do Sul possui a melhor infraestrutura e a segunda maior economia de todo continente africano (Kornegay 20I3). Os laços culturais e históricos, aliados aos atrativos econômicos e ao promissor cenário político no contexto internacional, despertaram no governo brasileiro uma oportunidade de expandir suas relações nos campos político, econômico e militar.

A política externa do governo Lula direcionou seus esforços considerando a África como um aspecto estratégico de grande importância. Durante seu governo, o eixo da política internacional brasileira deslocou-se parcialmente em direção ao hemisfério Sul. Sem abandonar os tradicionais aliados, o Brasil buscou ampliar seu leque de parcerias, voltando-se com maior ênfase para a África do Sul, onde acordos e tratados de cooperação foram implementados (Visentini 20II).

Sendo assim, ainda de acordo com Visentini, dentre as regiões que compõem o entorno estratégico, o país sul-africano tornou-se um dos mais expressivos para o Brasil, representando um dos eixos importantes da política externa brasileira nas primeiras décadas do século XXI, no que diz respeito ao desenvolvimento da Cooperação Sul-Sul.

Dessa forma, com o intuito de encontrar alternativas para aumentar seus poderes de negociação, os dois países em desenvolvimento começaram a criar novos arranjos de cooperação técnica e financeira a fim de substituir o tradicional modelo Norte-Sul de ajuda para o desenvolvimento. A partir disso percebeu-se um aumento progressivo de acordos comerciais e um estímulo à cooperação mútua entre os citados países.

Segundo Visentini (2OII), "a transição democrática sul-africana, consumada em I994, inaugurou um novo período nas relações Brasil-África do Sul. A partir de 2003 , as relações tornaram-se mais densas, o que permitiu o lançamento de iniciativas conjuntas". O acordo de cooperação com a África do Sul, assinado em 4 de junho de 2003, se constituiu em um dos mais completos que o Brasil firmou com uma nação africana. Dele foram estabelecidos, dentre outros objetivos, a troca de experiência no campo da pesquisa e desenvolvimento de materiais de defesa, contemplando um veículo aéreo não-tripulado (VANT); treinamentos conjuntos e aquisição de equipamentos militares; 
reuniões e estágios entre as instituições equivalentes de defesa (Neves 20I4).

No plano político, observou-se um aprofundamento das relações diplomáticas com o surgimento de alianças. Em 2003, foi criado o Fórum de Diálogo Índia-Brasil-África do Sul (IBAS) como um espaço de intercâmbio de conhecimento e fortalecimento de interesses comuns entre os países membros. Esse fórum político possibilitou o estreitamento das relações entre Brasil e África do Sul, abordando também aspectos relevantes para fomentar o diálogo, a consulta e o comércio no âmbito Sul-Sul, bem como combater a pobreza e promover a troca de tecnologia e de informação entre os membros.

Depois de cinco encontros de Cúpula e encontros ministeriais, o grupo consolidou um considerável repositório de posições comuns. Por intermédio da capilaridade política obtida por essa aliança, foi possível ao IBAS prestar auxílio à Guiné-Bissau, Haiti e Palestina, por exemplo. O Fundo IBAS, além de assistir os países do Sul, serve como importante instância de afirmação das políticas do grupo. A intenção do Brasil de obter um assento permanente no Conselho de Segurança das Nações Unidas, com o objetivo de multilateralizar a governança mundial, é apenas um dos motivos para o fomento de coalizões no eixo Sul-Sul (Pereira e Barbosa 2012, 64).

A partir de 2005, Brasil e África do Sul aumentaram sua interação diplomática e militar no âmbito do IBAS. ${ }^{\text {Io }}$ Houve um alinhamento das políticas de ambos os países em torno da cooperação Sul-Sul, como meio de atingir maior autonomia e proeminência internacional (Pereira e Barbosa 20I2, 73). A Declaração de Parceria Estratégica Brasil-África do Sul, assinada durante a visita de Estado do Presidente Lula à África do Sul, em junho de 20ıo, serviu para coroar o processo de aproximação entre os dois países, levando as relações a um novo patamar de excelência (Visentini 20II).

No que diz respeito às relações bilaterais na área de defesa, Brasil e África do Sul já haviam assinado, em 2003, um Acordo de Cooperação Militar, o Comitê Conjunto de Defesa Brasil-África do Sul. Os países têm mantido intercâmbios de formação de oficiais, realizam exercícios militares e fomentam a parceria no desenvolvimento de projetos tecnológicos. Dentre os principais produtos e serviços brasileiros que foram oferecidos à África do Sul naquela época destacam-se: Aeronaves de Patrulha (Embraer), Foguetes Astros (Avibras), Barcos de Patrulha (EMGEPRON), e a Tecnologia de Gerenciamento do

Io O Fórum IBAS, além de contribuir para a construção de uma nova arquitetura internacional, busca também aprofundar o conhecimento mútuo em áreas específicas, como Agricultura; Ciência e Tecnologia; Comércio e Investimentos; Cultura; Defesa; Desenvolvimento Social; Educação; Energia; Meio Ambiente e Mudança Climática; Saúde; Sociedade da Informação; Transporte; Turismo, entre outras (Costa Vaz e Flemes 20II). 
SIVAM $^{\mathrm{II}}$, por intermédio da empresa Atech ${ }^{\mathrm{I2}}$ (Martin et al. 20I4).

$\mathrm{Na}$ África do Sul, a cooperação militar abarca, além da instrução militar e de exercícios navais conjuntos, a dimensão tecnológica. Um dos temas mais destacados desse acordo bilateral é a construção do sistema de vigilância do Atlântico Sul por satélite oceanográfico e do protótipo A-Darter, que é um dos mais significativos projetos mantidos no exterior pela Força Aérea Brasileira. Sua importância estratégica deve-se à transferência efetiva de tecnologia e de conhecimentos acessórios que podem ter aplicação para fins civis em diversas áreas: agricultura, sensores, sistema de comunicação por rádio e veículos aéreos não tripulados (Escosteguy 20II).

O projeto do míssil A-Darter é fruto da parceria aeroespacial entre os dois países feita ao final de 2003 . As principais companhias envolvidas no projeto são as empresas privadas brasileiras Mectron, Avibras, Atech e Opto Eletrônica; e a sul-africana Denel Dynamics, pertencente a Denel Ltda., que cria e fabrica armamentos vendidos ao governo da África do Sul. Essa indústria de defesa estabeleceu uma fábrica no Brasil (Denel do Brasil), estreitando as relações comerciais e fortalecendo os acordos de cooperação estabelecidos entre os dois países (Martin et al. 2014, 32).

O desenvolvimento desse projeto teve início em 2007, com os custos do programa partilhados entre os dois países. O A-Darter encontra-se na etapa final de desenvolvimento; previa-se que os primeiros mísseis seriam entregues em fevereiro de 2016 para as forças aéreas do Brasil e África do Sul, com seis meses de atraso em relação ao prazo inicial. ${ }^{13}$ Os mísseis serão empregados em aeronaves da Força Aérea do Brasil e da África do Sul (Martin et al. 20I4). A relevância e o sucesso desse projeto contribuíram para o fortalecimento da relação entre as indústrias de defesa de ambos os países.

No contexto das relações entre Brasil e África do Sul, a Embraer tem

II Sistema de Vigilância da Amazônia (SIVAM): Projeto elaborado pelo Ministério de Defesa brasileiro, com a finalidade de monitorar o espaço aéreo da Amazônia.

I2 A indústria de defesa brasileira, durante as décadas de i980 e I990, enfrentou momentos de desaceleração, passando por um forte declínio ao final do referido período, tendo o ponto de inflexão o ano de 2003 , quando se iniciou o Governo Lula. A partir deste ponto, a política externa brasileira retomou a política de exportações militares, novamente priorizando as diretrizes governamentais nas relações com os países emergentes, entre eles a África do Sul e Angola (Abdenur e Souza Neto 20I4b).

I3 Em virtude do sigilo tecnológico, os sítios eletrônicos das empresas e órgãos envolvidos no desenvolvimento do A-Darter apresentam poucas informações. Foram utilizados os sites da "Defense Industry Daily" (<http://www.defenseindustrydaily.com/south-africa-brazil-to-develop-adarter-sraam-03286/>), e "Defesa Aérea e Naval" (<http://www.defesaaereanaval.com.br/ missil-a-darter-primeiras-entregas-ocorrerao-em-fevereiro-de-20ı6/>) para complementar as informações sobre o A-Darter. 
obtido significativa participação, tanto no campo comercial como na difusão de conhecimento tecnológico para a realização de projetos conjuntos. Além do projeto A-Darter, a Embraer também participa de estudos para o desenvolvimento de um avião cargueiro e de veículos aéreos não tripulados. $\mathrm{Na}$ área naval, os dois países participam, juntamente com a Índia, de exercícios navais no âmbito do India-Brazil-South Africa Maritime (IBSAMAR), promovendo maior integração entre a marinha brasileira e sul-africana, além de adestrar e capacitar seus efetivos por meio de exercícios navais conjuntos. (Albuquerque 2010).

No ano de 20Io, ocorreu a segunda edição do exercício naval IBSAMAR, realizado novamente na África do Sul, ponto mais próximo entre os três países, envolvendo numerosos meios (helicópteros das três marinhas, I2 navios, submarinos, entre outros). Além disso, o exercício previa ações de Guerra Antissubmarino, operações de busca e apreensão embarcada, reabastecimento em alto-mar e defesa antiaérea. Além de garantir um contato com técnicas navais novas e equipamentos tecnológicos mais atualizados utilizados pela África do Sul e Índia, esse tipo de exercício contribui para consolidar a presença da Marinha do Brasil no Atlântico Sul (Pereira e Barbosa 20I2).

A participação efetiva do Brasil no IBSAMAR tem possibilitado o preparo de parte de suas Forças Armadas para o desempenho de responsabilidades crescentes em operações internacionais de apoio à política exterior do Brasil. Tal participação não só atende a uma das diretrizes da END, como fortalece o sistema de segurança coletiva, contribuindo para a paz mundial e a defesa nacional ${ }^{\mathrm{I} 4}$ (Heleno e Martins 20I4).

A parceria Brasil-África do Sul envolve também o protocolo de intenções para fabricar o Lançador Múltiplo de Granadas de $40 \mathrm{~mm}$, entre a estatal brasileira IMBEL (Indústria de Material Bélico do Brasil) e a sul-africana Rippel Effect Weapon Systems Ltda. Ressalta-se que até o presente, apesar dos acordos e intenções estabelecidos entre os dois países, não houve qualquer contrato de venda firmado entre o Brasil e o país africano (SIPRI 20I6). Este tem, historicamente, como principais fornecedores de petrechos bélicos Alemanha, Estados Unidos, França e Reino Unido. Mais recentemente destacam-se as negociações de importação com o Canadá, Finlândia e Suíça (Martin et al. 20I4).

I4 Ressalta-se que Índia, Brasil e África do Sul celebraram um acordo de cooperação nuclear com fins pacíficos, buscando desarmamento nuclear e uso da tecnologia de defesa apenas para fins civis. Esse acordo foi estabelecido por meio do $\mathrm{G}_{3}$ (grupo formado pelos três países mencionados, criado em 2003, de caráter político, estratégico e econômico) (Neves 20I4). 


\section{Relações Brasil - Angola}

Após passar por um longo período de sofrimentos causados pelo colonialismo português e com a guerra civil, Angola hoje desponta como um dos países mais prósperos da África ${ }^{15}$ (Saraiva 2015). O cenário pós-guerra civil em Angola se mostrou propício para a política externa adotada pelo Brasil, a partir do Governo Lula (Saraiva 20I2). O discurso de "cooperação entre iguais" fez despertar os vínculos de identidade linguística para a harmonização de interesses nos dois lados do Atlântico. Com isso, Chaves (20I4) caracteriza que "as relações entre Brasil e Angola passaram a ser ditadas pelo soft power e hard power, do lado brasileiro, e pela recepção otimista, do lado angolano".

Um dos aspectos marcantes das relações entre Brasil e Angola foram os acordos de cooperação técnica. Apenas no primeiro ano de Governo Lula, foram assinados doze acordos desse tipo nas mais diversas áreas, mais marcadamente em saúde e educação (Visentini 20II).

Angola, com quem o Brasil assinou parceria estratégica em 2010, conta com aspectos relevantes nas relações bilaterais que têm facilitado as negociações entre os países: a presença de angolanos no Brasil e brasileiros em Angola; a atuação de multinacionais brasileiras; a participação do Brasil no levantamento da plataforma continental de Angola, por meio do Leplac-Angola; e o papel ativo de Angola na revitalização da ZOPACAS (Kornegay 20I3).

Além da cooperação mútua nos campos da política e da economia com Angola, o governo brasileiro também intensificou suas ações e parcerias estratégicas no campo da defesa, contribuindo para o crescimento da indústria do setor e proporcionando o aperfeiçoamento técnico-profissional militar de ambos os países (oferecimento de vagas em escolas preparatórias de oficiais a militares angolanos; treinamento a oficiais angolanos com vista à participação em operações de manutenção da paz; exercícios navais, entre outros) (Escosteguy 20II). Ainda sobre as relações industriais entre os dois países no campo da defesa, o Brasil tem incentivado a exportação de armamentos para o crescente mercado angolano. Destaca-se a venda de aeronaves A-29 Super Tucano, fabricada pela Embraer, para Angola, Burkina Fasso e Mauritânia (Silveira 20I2).

Abdenur e Souza Neto (20I4b, 229) destacam que "o principal interesse dos angolanos é que o Brasil auxilie o país a desenvolver a sua própria

I5 Segundo dados do Ministério do Desenvolvimento, Indústria e Comércio, nos últimos anos as exportações angolanas registraram expansão de $189 \%$, passando de US\$ 22, I bilhões em 2005, para alcançar o nível de US\$ 63,7 bilhões em 20I4, gerando elevadas taxas de crescimento para a economia angolana, devido à expansão do setor petrolífero e a retomada de atividades econômicas interrompidas ao longo de 40 anos de conflitos armados (MDIC 20I4). 
indústria nacional de defesa, reduzindo a dependência das Forças Armadas de Angola em relação à indústria estrangeira”. Em fevereiro de 20I3, este assunto foi debatido durante visita realizada pelo então Ministro da Defesa, Celso Amorim, acompanhado de representantes da indústria de defesa brasileira, quando em visita à capital angolana.

A cooperação brasileira em defesa também cresce via plataformas multilaterais. A agenda internacional entre Brasil e Angola manteve a CPLP como referência importante de concertação política-diplomática, utilizando-a também para assuntos de cooperação técnica, exportação de bens e serviços, saúde e ciência, defesa e segurança, entre outros (Chaves 20I4). A CPLP serve também como fórum de discussão sobre o potencial marítimo do Atlântico Sul para as parcerias comerciais, econômicas e de segurança. Alguns projetos dentro dessas áreas já foram incorporados em âmbito formal, como a recomendação do Conselho de Ministros da CPLP sobre os espaços oceânicos, em 2007 (Jorge 20II, I24).

No âmbito da CPLP, a cooperação entre as marinhas destes países tornou-se um elo efetivo para aproximação do grupo. No ano de 20Io, por exemplo, realizou-se o II Simpósio das Marinhas dos Países de Língua Portuguesa, no qual os diversos representantes dos países africanos lançaram as bases para uma maior cooperação com a indústria naval brasileira (Neves 2013).

Em maio de 20I2, foi realizado no Rio de Janeiro o III Simpósio das Marinhas da CPLP, cujo tema principal foi a questão da pirataria no Golfo da Guiné e a necessidade de apoio a países-membros da comunidade para o combate a esse tipo de crime. A Marinha do Brasil, juntamente com a marinha portuguesa, ofereceram assistência às marinhas de Angola, Cabo Verde e Guiné-Bissau, incluindo o fornecimento de apoio técnico e embarcações de patrulhamento. Um dos representantes da delegação brasileira sugeriu que a Marinha do Brasil poderia estabelecer uma linha de financiamento para a aquisição de embarcações por parte da Força Naval dos respectivos países africanos (Abdenur e Souza Neto 20I4b, 23I).

Em 20I3, o Brasil foi sede de uma operação conjunta com outros países de língua portuguesa: a Operação Felino ${ }^{16}$. Criada em 2000 no âmbito da CPLP, esse exercício militar tem o objetivo de treinar uma Força-Tarefa

I6 A operação foi realizada no Espírito Santo, coordenada pelo Estado-Maior Conjunto das Forças Armadas, do Ministério da Defesa, com o planejamento e execução a cargo da Marinha do Brasil. Participaram do exercício militar aproximadamente mil militares da Marinha do Brasil, Exército Brasileiro, Força Aérea Brasileira e dos demais países da CPLP, empregando 57 veículos; um Navio de Desembarque de Carro de Combate; um Navio Patrulha Oceânico; dois helicópteros Super Puma e um Esquilo; 44 viaturas e oito Carros Lagarta Anfíbio (Brasil 2013). 
Conjunta Combinada e permitir a interoperabilidade das Forças Armadas dos Estados-membros da CPLP, para o emprego em Operações de Paz e de Assistência Humanitária, sob a égide da Organização das Nações Unidas (Aguilar 20I3). O treinamento tem permitido maior aproximação entre as Forças Armadas envolvidas, contribuindo para o aprimoramento da capacitação técnico-científica no campo militar, além de fortalecer a cooperação entre os países participantes (Brasil 20I3).

Angola, um dos maiores produtores de petróleo no continente africano, assinou com o Brasil uma Declaração Conjunta de Parceria Estratégica e um Acordo de Cooperação em Defesa no ano de 20Io. Era previsto que tal fato possibilitasse maior estreitamento das relações entre as forças armadas e a indústria brasileira com o governo angolano, gerando inúmeras oportunidades de exportação entre os países, além da cooperação técnica-militar em assuntos de interesse de ambos os países, contribuindo para o desenvolvimento da indústria de defesa brasileira (Brasil 20I4; Saraiva 20I5).

Pesquisas no site Stockholm Internationl Peace Research Institute (SI$P R I$ ) demonstram que o acordo em questão gerou, até o momento, pequeno impacto na transferência de armamentos entre os dois países (SIPRI 20I6). Em 20II, Angola comprou seis Super Tucanos da EMBRAER, prática que remonta a contratos firmados entre o país africano com a empresa brasileira nas décadas de I980, I990 e 2000. Angola, que tinha, nas décadas de i970 e I980, como principais fornecedores de material bélico (em sua grande maioria de segunda mão) a antiga União Soviética e Portugal, nas décadas de I990 e 2000, passou a importar petrechos bélicos da Rússia e de antigas repúblicas soviéticas (também equipamentos de segunda mão). Em 2013, Angola firmou a compra de mais de 40 veículos blindados sul-africanos, equipados com motores chineses. Os dados apontam mais para uma "parceria" de Angola com os BRICS do que propriamente com o Brasil.

\section{Conclusão}

As relações bilaterais do Brasil com África do Sul e Angola, nos campos da política, da economia e da defesa, mesmo que numa intensidade aquém do desejado, têm ocorrido conforme estabelecido na PND e na END. Assim, o Atlântico Sul, além de servir ao Brasil como palco de expansão econômica e aproximação política com os citados países, atua também como área estratégica para o aprimoramento das capacidades militares de suas Forças Armadas, em especial da Marinha, fortalecendo a cooperação mútua entre os países e impulsionando a projeção do Brasil no cenário internacional. 
Os impactos da descoberta das reservas do pré-sal ampliaram significativamente as expectativas do país alcançar uma posição de destaque no comércio internacional, fazendo com que a estabilidade do Atlântico Sul seja vital para a defesa do país. Além disso, as relações bilaterais do Brasil com África do Sul e Angola reforçam a importância da manutenção da segurança nesse entorno estratégico, para que o intercâmbio comercial, diplomático e militar tenha continuidade dentro da concepção pacífica que já vem ocorrendo nos últimos anos.

No caso brasileiro, o aumento de sua presença no Atlântico Sul se faz sem conflitos de vizinhança e segundo estratégias que combinam princípios e movimentos efetivos nos campos da cooperação e da dissuasão. Tal situação é reforçada pela presença do Brasil como integrante da ZOPACAS, que tem buscado, dentre outros objetivos, o compromisso de manutenção do Atlântico Sul como zona isenta de conflitos militares, contribuindo para a segurança desse entorno estratégico.

A inflexão nos rumos do desenvolvimento do país na direção do Atlântico Sul nos últimos anos expressa a conjugação de vetores de largo espectro e longa duração. Essa conquista vem sendo processada pela aplicação de uma estratégia que combina ações contínuas no campo diplomático, esforço nacional de pesquisa na ampla área das ciências do mar e investimentos que visam fortalecer a capacidade militar do país para fazer frente aos seus desafios de segurança e defesa em geral e no Atlântico Sul em particular.

No âmbito do IBAS, a relação entre Brasil e África do Sul (juntamente com a Índia) está cada vez mais fortalecida. Essa nova realidade poderá constituir uma nova distribuição de poder que contribuirá para a manutenção da segurança no Atlântico Sul. Os exercícios militares realizados por meio do IBSAMAR comprovam essa proposta. Além disso, o fortalecimento das relações entre os países no Atlântico Sul poderá contribuir para a expansão do intercâmbio comercial e militar utilizando-se inclusive de rotas até o Oceano Índico.

O apoio do governo brasileiro, seja estruturando acordos de defesa ou por meio das visitas de Estado realizadas no período considerado, tem demonstrado uma atitude mais progressiva do país frente a seu papel no cenário internacional, favorecendo o surgimento de oportunidades para a renascente indústria de defesa no mercado africano. Dessa forma, a crescente aproximação entre as forças armadas brasileiras, angolanas e sul-africanas, cria uma cultura favorável ao emprego de material bélico brasileiro por parte desses países, contribuindo para o desenvolvimento do parque industrial brasileiro ao garantir um ganho de escala na produção de armamentos.

Com a reformulação das capacidades militares propostas na PND, 
END e LBDN, especialmente no componente marítimo, o Brasil ampliará suas potencialidades para inserção e projeção de poder no cenário do Atlântico Sul. Dessa forma, torna-se fundamental que a política externa acompanhe esse desenvolvimento e flexibilize suas concepções históricas sem abandonar o seu caráter conciliatório, ao tempo em que adquire consciência do novo patamar militar que o Brasil almeja atingir nas próximas décadas.

A busca pelo aperfeiçoamento do poder militar brasileiro servirá para dar alternativas de ação ao país, além de reforçar a soberania nacional e a autonomia internacional, sempre dando significativa ênfase às ações que visem à manutenção da segurança e estabilidade no Atlântico Sul. Portanto, as relações bilaterais com a África do Sul e Angola assumem um papel fundamental, pois caracterizam-se como um meio de engajamento e aprofundamento de laços, podendo cooperar significativamente para moldar o ambiente estratégico regional e internacional, de forma a conter, resolver ou evitar possíveis conflitos que venham a ocorrer nessa região.

\section{REFERÊNCIAS}

Agência Brasileira de Cooperação (ABC). 20Io. Cooperação brasileira para o desenvolvimento internacional. Instituto de Pesquisa Econômica Aplicada (IPEA). Acesso em io de junho de 20I5. www.abc.gov.br/api/ publicacaoarquivo/328.

Agência Brasileira de Cooperação (ABC). 20ı2. Projetos de Cooperação Sul-Sul. Ministério das Relações Exteriores. Acesso em 3 de maio de 20I5. www.abc.gov.br/projetos/pesquisa?intldTipCoopera$\mathrm{caO}=\mathrm{I} \&$ intldPais $=\mathrm{I} 2$

Abdenur, Adriana E., e Souza Neto, Danilo. M. 20I4a. "O Brasil e a cooperação em defesa: a construção de uma identidade regional no Atlântico Sul." Revista Brasileira de Política Internacional 57:5-2I.

Abdenur, Adriana E., e Souza Neto, Danilo. M. 20I4b. "O Atlântico Sul e a cooperação em defesa entre o Brasil e a África.” In O Brasil e a Segurança no seu Entorno Estratégico: América do Sul e Atlântico Sul, organizado por Reginaldo M. Nasser, e Rodrigo F. de Moraes 2I5238. Brasília: Instituto de Pesquisa Econômica Aplicada.

Acioly, Luciana, e Moraes, Rodrigo F. 20II. Prospectiva, estratégias e cenários globais: visões de Atlântico Sul, África Lusófona, América do Sul e Amazônia. Brasília: Instituto de Pesquisa Econômica Aplicada.

Aguilar, Sérgio L. C. 20I3. "Atlântico Sul: as relações do Brasil com os países africanos no campo de segurança e defesa." Austral: Revista Brasilei- 
ra de Estratégia e Relações Internacionais 2(4): 49-7I. Acesso em 7 de julho de 20I5. www.seer.ufrgs.br/index.php/austral/article/download/41288/26967

Albuquerque, Eduardo. S. 2oio. "A Geopolítica de Defesa Brasileira.” Revista de Geopolítica I:46-59. Acesso em I5 de abril de 2015. www.revistageopolitica.com.br/index.php/revistageopolitica/article/view/3/5

Brasil. Ministério da Defesa. 2012. Política de Defesa Nacional. Acesso em I9 de março de 2015. www.defesa.gov.br/arquivos/estado_e_defesa/ END-PND_Optimized.pdf

Brasil. Ministério da Defesa. 2012a. Estratégia Nacional de Defesa. Acesso em I9 de março de 20I5. www.defesa.gov.br/arquivos/estado_e_defesa/ END-PND_Optimized.pdf

Brasil. Ministério da Defesa. 2orzb. Livro Branco de Defesa Nacional. Acesso em 25 de março de 2015. www.defesa.gov.br/arquivos/2012/meso7/ lbdn.pdf

Brasil. Ministério da Defesa. 2013. Felino 2013: países da CPLP realizam exercício conjunto na costa brasileira. Acesso em 22 de março de 2015. www.defesa.gov.br/index.php/noticias/44I2-I7-09-20I3-defesa-felino-20I3-paises-da-cplp-realizam-exercicio-conjunto-na-costa-brasileira

Brasil. Ministério do Desenvolvimento, Indústria e Comércio Exterior (MDIC). 20Io. Oportunidades de negócios em serviços: Brasil e Angola. Acesso em I7 de junho de 20I5. www.desenvolvimento.gov.br//arquivo/dwnl_t257766509.pdf

Brasil. Ministério das Relações Exteriores. 20ıo. Balanço da política externa, 2003- 2010: relações com a África. Acesso em II de agosto de 2015. www.i3gov.planejamento.gov.br/textos/livro6/6.I_Politica_Externa. pdf

Brasil. Ministério das Relações Exteriores. 20I4. Guia de Negócios: Angola. Acesso em I2 de agosto de 2015. www.investexportbrasil.dpr.gov.br/ arquivos/Publicacoes/ComoExportar/GNAngola.pdf

Cervo, Amado L. 2008. Inserção internacional: formação dos conceitos brasileiros. São Paulo: Editora Saraiva.

Chaves, Leonildes N. 20I4. O papel da lusofonia nas relações entre Brasil e Angola. Revista Perspectivas do Desenvolvimento 2: I-28. Acesso em 2 de setembro de 2015. www.periodicos.unb.br/index.php/perspectivasdodesenvolvimento/article/view/ı1885/8982

Costa Vaz, Alcides, e Flemes, Daniel. 20II. "Security Policies of India, Bra- 
zil and South Africa." Regional Security Contexts as Constraints for a Common Agenda. Hamburgo: Instituto Alemão de Estudos Globais e de Área. www.giga-hamburg.de/de/system/files/publications/ wpi6o_flemes-vaz.pdf

Costa, Wanderley M. da. 20I2. "Projeção do Brasil no Atlântico Sul: Geopolítica e Estratégia." Revista USP 95:9-22. Acesso em 4 de maio de 20I5. www.revistas.usp.br/revusp/article/viewFile/52234/56270

Dougherty, James. E., e Pfaltzgraff, Robert. L. 2003. Relações internacionais: as teorias em confronto. Lisboa: Gradiva.

Escoteguy, Pedro. 20II. "A nova arquitetura africana de paz e segurança: implicações para o multilateralismo e para as relações do Brasil com a África." Fundação Alexandre de Gusmão Biblioteca Virtual. Acesso em 8 de maio de 20I5. www.funag.gov.br/loja/download/847-Nova_arquitetura_africana_de_paz_e_seguranca_A.pdf

Garcia, Ana S., e Kato, Karina Y. M. 20I4. "A história da caça ou do caçador? Reflexões sobre a inserção do Brasil na África." Tensões Mundiais ıo: I45-I7I

Garcia, Ana. E. S. 2012. "A internacionalização de empresas brasileiras durante o governo Lula: uma análise crítica da relação entre capital e Estado no Brasil contemporâneo." FUNAG: Instituto de Pesquisas de Relações Internacionais. Acesso em 4 de junho de 20I5. www.funag. gov.br/ipri/btd/index.php/9-teses/I452-a-internacionalizacao-de-empresas-brasileiras-durante-o-governo-lula-uma-analise-critica-da-relacao-entre-capital-e-estado-no-brasil-contemporaneo

Goldoni, Luiz R. F., e Domingos Neto, Manuel. 2oI4. Perspectiva da cooperação militar entre os BRICS. Tensões Mundiais Io:366-377. Acesso em I8 de maio de 20I5. www.tensoesmundiais.net/index.php/tm/ article/viewFile/355

Gonçalves, T; Corbellini, M. 20ı4. "A estratégia marítima brasileira contemporânea para o Atlântico Sul.” Revista do Centro de Estudos e Pesquisas Econômicas 40: 249-277. Acesso em II de julho de 20I5. www.online.unisc.br/seer/index.php/cepe/article/view/5113

Guerra, Wilson B. 20II. “O Brasil e a Segurança do Atlântico Sul.” Instituto da Defesa Nacional: Nação e Defesa i28: 67-76. Acesso em I4 de agosto de 20I5. www.comum.rcaap.pt/bitstream/I0400.26/4745/I/I28_ WilsonBarbosaGuerra.pdf

Heleno, Maurício. G. B., e Martins, Mônica. D. 20I4. "Cooperação ou dominação? A política externa do governo Lula para a África.” Tensões Mundiais Io:I25-I43. Acesso em abril de 20I5. www.tensoesmun- 
diais.net/index.php/tm/article/view/347

Jorge, Nedilson. R. 20II. "O Brasil e a comunidade lusófona na África: relações atuais e perspectivas de aprofundamento." In Prospectiva, estratégias e cenários globais: visões de Atlântico Sul, África Lusófona, América do Sul e Amazônia, organizado por Luciana Acioly, e Rodrigo F. de Moraes II7-I26. Brasília: Instituto de Pesquisa Econômica e Aplicada (IPEA).

Kornegay, Francis A. 20I3. "África do Sul, o Atlântico Sul e a equação IBAS-BRICS: o espaço transatlântico em transição.” Austral: Revista Brasileira de Estratégia e Relações Internacionais 2: 79-106. Acesso em 3 de maio de 20I5. www.seer.ufrgs.br/index.php/austral/article/download/35010/23929

Martin, Keith, e Carreta, Beatriz M., e Terano, Rafaella Y. 20I4. "A Indústria de Defesa e as Relações Brasil-África: Sucessos e Desafios". In Brasil-África, organizado por Leonardo P. Neves 23-46. Rio de Janeiro: Centro Brasileiro de Relações Internacionais (CEBRI).

Menezes, Wagner. 20I5. "O Direito do Mar." Fundação Alexandre de Gusmão Biblioteca Virtual. Acesso em 8 de setembro de 20I5. www.funag. gov.br/loja/download/ııI9-O_Direito_do_Mar.pdf

Miyamoto, Shiguenoli. I987. "Atlântico Sul: zona de paz e de cooperação?” Lua Nova: Revista de Cultura e Política. Acesso em iI de julho de 2015. www.scielo.br/scielo.php?script=sci_arttext\&pi$\mathrm{d}=$ SoI02-6445198700010005

Nasser, Reginaldo. M., e Moraes, Rodrigo. F. 20I4. O Brasil e a Segurança no seu entorno estratégico: América do Sul e Atlântico Sul. Brasília: Instituto de Pesquisa Econômica Aplicada.

Neves, André L. V. 20I3. "Atlântico Sul: Projeção estratégica do Brasil para o Século XXI." Centro de Estudos Estratégico do Exército. Brasília: 2013.

Neves, Leonardo P. 20I4. "Brasil-Africa." Centro Brasileiro de Relações Internacionais. Acesso em I4 de julho de 2015. www.cebri.org/portal/ publicacoes/cebri-dossi\%C3\%AA/brazil-africa

Penha, Eli. A. 2oir. Relações Brasil-África e Geopolítica do Atlântico Sul. Salvador: Editora EDUFBA.

Pereira, Analúcia D, e Barbosa, Luíza C. P. 20ı2. "O Atlântico Sul no contexto das relações Brasil-África." Revista Século XXI de Relações Internacionais 3:59-77. Acesso em 20 de julho de 2015. sumario-periodicos. espm.br/index.php/seculo2I/article/viewFile/I8 $36 /$ II3

Saraiva, José F. S. 2012. África parceira do Brasil Atlântico: relações interna- 
cionais do Brasil e da África no início do século XXI. Belo Horizonte: Editora Fino Traço.

Saraiva, José F. S. 20I5. A África no século XXI : um ensaio acadêmico. Brasília: FUNAG.

Silva, Antônio R. A. 20I4. "O Atlântico Sul na perspectiva da Segurança e Defesa." In O Brasil e a Segurança no seu Entorno Estratégico: América do Sul e Atlântico Sul, organizado por Reginaldo M. Nasser, e Rodrigo F. de Moraes I99-2I3. Brasília: Instituto de Pesquisa Econômica e Aplicada (IPEA).

Silva, Alexandre P. da. 20I3. "O novo pleito brasileiro no mar: a plataforma continental estendida e o Projeto Amazônia Azul." Revista Brasileira de Política Internacional 56:I04-I2I. Acesso em 25 de abril de 20I5. Www. scielo.br/scielo.php? pid=S0034-73292013000100006\&script=sci_abstract\&tlng=pt

Silveira, Virgínia. 20I2. "Embraer fecha venda de Super Tucano para três países da África." Valor Econômico. Acesso em 23 de agosto de 2015. www.valor.com.br/empresas/2591312/embraer-fecha-venda-super-tucano-para-tres-paises-da-africa

SIPRI. 20I6. Stockholm Internationl Peace Research Institute. Arms Transfer Database. Acesso em ig de fevereiro de 20ı6. www.armstrade.sipri. org/armtrade/page/trade_register.php

Visentini, Paulo F. 2oIr. África do Sul - O Livro na Rua. Brasília: Editora Thesaurus.

Visentini, Paulo F. 20I3. A projeção internacional do Brasil: 1930-2012: diplomacia, segurança e inserção na economia mundial. Rio de Janeiro: Elsevier - Campus.

Wiesebron, Marianne. 2013. "A Amazônia Azul: Pensando a Defesa do Território Marítimo Brasileiro." Austral: Revista Brasileira de Estratégia e Relações Internacionais 2:I07-I3I. Acesso em I4 de agosto de 20I5. www.seer.ufrgs.br/index.php/austral/article/download/35039/23930 


\section{RESUMO}

Tendo em vista a defesa de um de seus espaços vitais (o Atlântico Sul) e buscando também maior proeminência internacional, o Brasil tem intensificado suas relações com o continente africano. O presente trabalho tem por objetivo analisar as relações bilaterais do Brasil com África do Sul e Angola, destacando seus efeitos para a manutenção da segurança no Atlântico Sul. São investigados a articulação crescente entre as políticas externa e de defesa brasileiras, os acordos de cooperação militar, e a realização de exercícios navais conjuntos.

\section{PALAVRAS-CHAVE}

Atlântico Sul; Segurança; Brasil; África do Sul; Angola.

Recebido em o8 de abril de 2016. Aprovado em 27 de julho de 2016. 